\title{
Serum IgG antibodies from healthy subjects up to 100 years
}

\section{old react to JC polyomavirus.}

*Ilaria Bononi ${ }^{1},{ }^{*}$ Elisa Mazzoni ${ }^{1},{ }^{*}$ Silvia Pietrobon ${ }^{1}$, Marco Manfrini ${ }^{1}$, Elena Torreggiani ${ }^{1}$, Marika Rossini $^{1}$, Francesca Lotito ${ }^{1}$, Giovanni Guerra ${ }^{2}$, Paola Rizzo, ${ }^{1}$ Fernanda Martini ${ }^{1 \wedge}$, Mauro Tognon ${ }^{1 \wedge}$

${ }^{1}$ Department of Morphology, Surgery and Experimental Medicine, Section of Pathology, Oncology and Experimental Biology, School of Medicine, University of Ferrara, Ferrara, Italy

${ }^{2}$ Clinical Laboratory Analysis, University Hospital of Ferrara, Ferrara, Italy

*These authors equally contributed to the work

${ }^{\wedge}$ Correspondence to: Mauro Tognon or Fernanda Martini, Department of Morphology, Surgery and Experimental Medicine, Section of Pathology, Oncology and Experimental Biology, Laboratories of Cell Biology and Molecular Genetics, School of Medicine, University of Ferrara, Ferrara 44121, Italy.

E-mail: tgm@unife.it (M.T.); mrf@unife.it (F.M.)

\section{KEYWORDS}

Antibody, serum, prevalence, titer, JC virus (JCPyV) 
JC polyomavirus (JCPyV) was identified in 1971 in the brain tissue of a patient (J.C.) affected by the progressive multifocal leukoencephalopathy (PML). JCPyV encodes for the oncoproteins large $\mathrm{T}$ antigen (Tag) and small t-antigen (tag). These oncoproteins are responsible of the cell transformation and tumorigenesis in experimental animals. JCPyV is ubiquitous in human populations. After the primary infection, which is usually asymptomatic, JCPyV remains lifelong in the host in a latent phase. Its reactivation may occur in heathy subjects and immunocompromised patients. Upon reactivation, JCPyV could reach (i) the CNS inducing the PML, (ii) the kidney of transplant patients causing the organ rejection. Association between JCPyV, which is a small DNA tumor virus, and gliomas and colorectal carcinomas has been published. In the present investigation, we report on a new indirect ELISA with two specific synthetic peptides mimicking JCPyV VP1 immunogenic epitopes to detect specific serum IgG antibodies against JCPyV. Serum samples of healthy subjects $(n=355)$ ranging 2-100 years old, were analyzed by this new indirect ELISA. The linear peptides VP1 K and VP1 N resemble the natural JCPyV VP1 capsidic epitopes constituting a docking site for serum antibodies. Data from this innovative immunologic assay indicate that the overall prevalence of JCPyV-VP1 antibodies in healthy subjects is at $39 \%$. The innovative indirect ELISA with JCPyV VP1 mimotopes seems to be a useful method to detect specific IgG antibodies against this virus, without cross-reactivity with the closely related SV40 and BKPyV polyomaviruses. 


\section{INTRODUCTION}

$\mathrm{JC}$ virus (JCPyV) is a polyomavirus, which was identified in 1971 in the brain tissue of a patient (J.C.) affected by progressive multifocal leukoencephalopathy (PML) (Padgett et al., 1971), a severe demyelinating disease of the central nervous system (CNS) (White et al., 2016).

JCPyV is characterised by double strand, circularly closed 5.13 Kb DNA (Pinto and Dobson, 2014). The JCPyV genome contains two approximately equal sized regions, known as early and late transcription units. The transcription of both units initiates from a common non-coding control region (NCCR), which contains the origin (ORI) of DNA replication. Early transcription proceeds in a counter clockwise direction, while late region transcription occurs clockwise on the complementary DNA strand. JCPyV early region encodes main, alternatively spliced, mRNAs for large $\mathrm{T}$ antigen (Tag) and small t-antigen (tag). Tag and tag are viral oncoproteins, which are responsible for the transformation of different histotypes and tumorigenesis cells in experimental animals. JCPyV early region encodes three additional forms of the $\mathrm{T}$ antigen with distinct molecular weights $\left(\mathrm{T}_{135}, \mathrm{~T}_{136}, \mathrm{~T}_{165}\right.$ ) (Bollag et al., 2000; Frisque et al., 2003; Prins and Frisque, 2001; Trowbridge and Frisque, 1995) alongside Tag and tag. JCPyV late region codes for the viral capsid structural proteins (VP) VP1, VP2 and VP3 and a small regulatory protein, known as agnoprotein. $\mathrm{JCPyV}$, which is ubiquitous in human populations world-wide, has a prevalence of up to $80 \%$, depending on the research and population in question (Egli et al., 2009; Knowles, 2006; Viscidi et al., 2011). After primary infection, which is usually asymptomatic, JCPyV remains lifelong in the host in a latent phase (Kean et al., 2009; Knowles, 2006; Stolt et al., 2003). Reactivation may occur in normal subjects and immunodepressed/suppressed patients (Boukoum et al., 2016; Delbue et al., 2013; Rodio et al., 2016).

Several studies have reported an association between human tumors and JCPyV. The main cancer histotypes, tested JCPyV-positive, are gliomas of different kinds and colorectal carcinomas (Del 
Valle et al., 2002; Delbue et al., 2017; Toumi et al., 2017). It should be recalled that other investigators have not detected JCPyV footprints in human tumors (Newcomb et al., 2004).

It has been suggested, that oncogenesis in vivo is driven by Tag and tag oncoprotein expression, as well as cellular dysregulated pathways, involving key gene products, such as beta-catenin and p53 (Ripple et al., 2014). In addition, JCPyV Tag is a mutagenic and clastogenic protein, which induces chromosomal abnormality in human cells, thus favoring chromosome instability, oncogene activation and loss of tumour suppressor gene functions (Ferenczy et al., 2012; Ricciardiello et al., 2003). The World Health Organization (WHO) has classified JCPyV as "2a, i.e. possibly carcinogenic to humans" (Bouvard V, 2012).

JCPyV has been detected in different tissues, including the CNS, lymphoid tissues and kidney. JCPyV may reactivate/infect CNS inducing PML, causing the death of up to $50 \%$ of affected patients (White et al., 2016). JCPyV neurotropism was responsible for some PML cases arising in patients affected by multiple sclerosis (MS) treated with biological drugs, which inhibited the immune system in the host (Clerico et al., 2017). Indeed, PML generally occurs in severely immune-compromised individuals, as well as in some patients receiving certain immunosuppressive biological drugs (Clavel et al., 2017; Plavina et al., 2014). As a result MS patients, who have been treated with monoclonal antibodies, which depress their immune system, are observed for JCPyV reactivation by measuring their serum specific immunoglobulin $G$ ( $\operatorname{IgG}$ ) levels (Hegen et al., 2017). In MS patients, biological drug withdrawal is suggested when JCPyV IgG levels reach dangerous threshold limits. (Hegen et al., 2017). Moreover, JCPyV may cause the organ transplant rejection in kidney transplant patients (Delbue et al., 2013).

At present, a two step indirect ELISA employing virus-like proteins (VLPs), represented by selfassembled recombinant VP1 molecules, is used to detect serum IgG antibodies against JCPyV (Clausi et al., 2015). However, JCPyV VP1/VLP shares common antigens with other homologous polyomaviruses, such as BK (BKPyV) and simian virus 40 (SV40). These ELISA methods with recombinant JCPyV VP1 or virus-like particles (VLP) have given cross-reactivity with other 
polyomaviruses (Barbanti-Brodano et al., 2006; Viscidi et al., 2003). To date, in order to avoid the cross-reactivity among polyomaviruses, serum samples are pre-adsorbed with homologue VLPs during the first step of the method, whereas samples are tested against JCPyV VLPs in the second step. This two step procedure is (i) cost effective, but (ii) long and tedious, whereas (iii) the JCPyV antibody titer level could be lowered during the pre-absorption step involving polyomavirus antigens.

The present investigation reports on a new indirect ELISA with two specific synthetic peptides, which mimic JCPyV VP1 antigens. These mimotopes or JCPyV VP1 synthetic peptides have low homology with corresponding BKPyV and SV40 VP1 antigens and hundreds of their variants as well as less homologous polyomaviruses. This new immunological assay is specific for JCPyV serum IgG antibody detection. Indeed, indirect ELISA does not cross-react with homologous BKPyV and SV40 polyomaviruses.

Herein, serum samples of healthy subjects were analyzed using this new indirect ELISA in order to detect specific serum IgG antibodies against JCPyV. In addition, the specificity of the results obtained with this innovative indirect ELISA were verified by comparing the immunological data with the results obtained by Haemagglutination Inhibition (HAI) assay, as recently reported (Pietrobon et al., 2017b) 


\section{MATERIALS AND METHODS}

\section{Human serum samples}

Serum samples $(\mathrm{n}=355)$ were collected from healthy subjects (HS) at the Clinical Laboratory Analysis, University Hospital of Ferrara. Sera were taken from discarded laboratory analysis samples, before incineration, after routine analyses. Hospital records annotated these serum samples as belonging to healthy subjects. Indeed, blood analysis parameters were all in the normal index range. Sera were collected anonymously, coded with indications of age and gender only. The the County Ethical Committee, Ferrara, approved the project. Written informed consent was obtained from subjects at the time of the hospital admission. All serum samples were stored at $-80^{\circ} \mathrm{C}$ until testing. Randomly chosen serum samples $(n=89)$ were also analyzed by Haemagglutination Inhibition (HAI) assay, as control (Pietrobon et al., 2017a; Pietrobon et al., 2017b; Portolani et al., 1974).

\section{Synthetic peptides}

\section{Peptide in-silico structural analysis}

Amino acid (a.a.) sequences of JCPyV viral capsid protein 1 (VP1), peptide K (VP1 K) and VP1 peptide N (VP1 N), were characterized by stable secondary structure formation. The analysis was carried out using the PSIPRED server (Bryson et al., 2005; Jones, 1999; Wang et al., 2007). Moreover, peptide sequences were mapped on native virion proteins to verify structural similarities. JCPyV VP1, in its monomeric form, was obtained from PDB (ID: 3NXG) (Berman et al., 2000; Neu et al., 2010). Molecular visualisations were performed using PyMOL (PyMOL Molecular Graphics System, Version 1.3, Schrödinger, LLC). Computational tools were available through the ExPASy server (Gasteiger et al., 2003). 


\section{JCPyV VP1 Mimotopes}

Computer-assisted analyses enabled 2 specific JCPyV peptides to be selected from the late viral region by comparing viral capsid proteins 1 (VP1) from JCPyV, with amino acids from BKPyV and SV40 polyomaviruses, which are highly homologous to JCPyV, as well as with other less homologous polyomaviruses (http://blast.ncbi.nlm.nih.gov).

The a.a. sequences of the two peptides VP1 K and VP1 N are:

(a) VP1 K: $\mathrm{NH}_{2}-\mathrm{KSISISDTFESDSPNRD} \mathrm{-} \mathrm{COOH} \mathrm{(17} \mathrm{a.a.,} 1646$ - 1696);

(b) VP1 N: $\mathrm{NH}_{2}$ - LMNVHSNGQATHDNGAGK - COOH (18 a.a., 1820-1873).

VP1 K and VP1 N mimotopes were selected because they reacted specifically in indirect E.L.I.S.A. testing (see below) with a rabbit hyperimmune serum that had been experimentally immunized with JCPyV (positive control serum). BKPyV and SV40 hyperimmune sera did not react with VP1 K and VP1 $\mathrm{N}$ peptides (negative control sera). The a.a. residues of the 2 specific JCPyV peptides exhibit low homology with BKV and SV40 VPs. The human peptide hNPS, a.a. sequence $\mathrm{NH}_{2}-$ SFRNGVGTGMKKTSFQRAKS - COOH (20 a.a. residues), was employed as a negative control peptide (Guerrini et al., 2010). Peptides, synthesized by standard procedures, were purchased from UFPeptides s.r.l. (Ferrara, Italy).

\section{Indirect Enzyme-Linked Immunosorbent Assay (ELISA)}

Indirect ELISA was developed and standardized to detect specific antibodies against JCPyV VP1 in human sera using VP1-K and VP1-N synthetic peptides. Peptide coating. Plates were coated with $5 \mu \mathrm{g}$ of the selected peptide for each well and diluted in $100 \mu \mathrm{l}$ of Coating Buffer (Candor Bioscience, Germany) at $4{ }^{\circ} \mathrm{C}$ for 16 hours. Peptide blocking. Blocking was made with $200 \mu 1 /$ well of the Blocking Solution (Candor Bioscience, Germany) at $37^{\circ} \mathrm{C}$ for 90 min. Primary antibody adding. Several wells were covered with $100 \mu$ of serum sample diluted 1/20 in Low Cross-Buffer (Candor Bioscience, Germany). JCPyV positive-control was represented by an immune rabbit 
serum containing anti-JCV antibodies, whereas JCPyV negative controls were represented by human immune sera anti-SV40 VPs and anti-BKV VPs, which were found to be JCPyV-negative in previous studies using the Haemagglutination Inhibition (HIA) assay (Maginnis et al., 2013; Pietrobon et al., 2017b; Portolani et al., 1974). Each sample was analyzed three times in duplicate wells. Secondary antibody adding. The solution contained a goat anti-human or anti-rabbit IgG heavy and light chain specific peroxidase-conjugate (Calbiochem-Merck, Germany) diluted 1:10,000 in the Low Cross-Buffer. Dye treatment and spectrophotometric reading. Samples were treated with $100 \mu \mathrm{l}$ of 2,2'-azino-bis 3-ethylbenzthiazoline-6-sulfonic acid (ABTS) solution (SigmaAldrich, Milan), for $45 \mathrm{~min}$. at RT, and then read on a spectrophotometer (Thermo Electron Corporation, model Multiskan EX, Finland) at a wavelength $(\lambda)$ of $405 \mathrm{~nm}$. Colour intensity in wells was determined by optical density (OD) where the immune-complexes formed. Cut-off determination. Cut-off values were determined for each assay using an OD reading of the three negative control sera that were added to the standard deviation and multiplied three times (+3SD). The three JCPyV negative control sera were selected from those below the cut-off value determined using second-degree polynomial regression by plotting the ranked net OD individual values for each peptide (Touze et al., 2010). A tendency curve was drawn from a second-degree polynomial regression for VP1 $\mathrm{K}$ and $\mathrm{N}$ peptides, as published before for MCPyV and BKPyV virus-like particles (VLPs) (Coursaget et al., 2013; Touze et al., 2010).

Sera with JCPyV antibodies were considered VP-positive upon reacting to both peptides of the late region and when sera that had been analyzed three times by indirect ELISA testing gave the same positive result (Corallini et al., 2012; Martini et al., 2013; Mazzoni et al., 2012; Taronna et al., 2013). 


\section{JCPyV Haemagglutination and Haemagglutination-inhibition Assays}

The JCPyV viral working stock for the Haemagglutination Inhibition (HAI) assay was purchased from the American Type Culture Collection (ATCC, VR-1583). The viral titer, determined by HAI

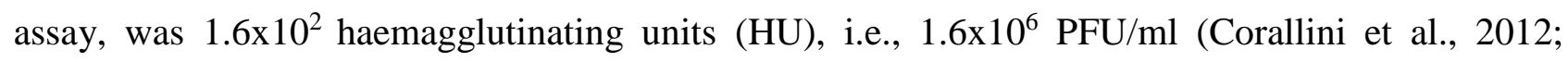
Portolani et al., 1974). JCPyV was employed as an antigen in both Haemagglutination (HA) and HAI assays. JCPyV HA and HAI titrations were carried out as recently described (Pietrobon et al., 2017b). This assay allows the detection of immune sera against JCPyV, which abolish the viral agglutination property exerted in human erythrocytes group $0, \mathrm{Rh}+$. The $\mathrm{HA}$ titer was calculated based on the highest virus dilution that led to complete haemagglutination, whereas the HAI titer was the highest dilution of each immune serum sample completely inhibiting viral HA.

The comparison between the indirect ELISA and HAI test is of a fundamental significance. Indeed, HAI assay is highly specific because only JCPyV-positive sera can inhibit the capability of JCPyV virions to haemagglutinate human erythrocytes group $0, \mathrm{Rh}+$. There is not HAI cross-reactivity by other polyomaviruses, such as $\mathrm{BKPyV}$. Indeed, the BKPyV haemagglutination property is not inhibited by JCPyV-positive sera, whereas SV40 does not own hemagglutination activity (Mazzoni et al., 2012).

\section{Statistical analysis}

Age group differences were statistically evaluated. Statistical analyses were performed using Prism 4.0 software (GraphPad, San Diego, CA). Data are presented as a percentage of the positive samples. $95 \%$ confidence intervals for the percentage of positive samples are also reported. Proportional differences were calculated by $\chi^{2}$ testing for independence in the contingency tables. The small sample size was statistically analysed using $\chi^{2}$ with Yates' correction. The serologic profile of serum antibody reactivity to JCPyV mimotopes was statistically analyzed using Anova and Tukey's comparison test. $P$ value $<0.05$ was considered to be statistically significant. The 
interun variability was analyzed with Anova and Holm Sidak corrected for multiple comparison, whereas the intrarun variability was analyzed with t-test. 


\section{Results}

\section{Peptide in-silico structural analysis}

Computational analysis, which was conducted using the PSIPRED server, showed that the two linear peptides are characterised toward secondary structures as follows: VP1 K shows manly a random coil secondary structure and contains two beta sheet domains from a.a. 3 to a.a. 5 , i.e. ${ }_{3} \mathrm{ISI}_{5}$, and from a.a. 7 to a.a. 9 , i.e. ${ }_{7} \mathrm{DTF}_{9}$, respectively. VP1 $\mathrm{N}$ shows mainly a random coil secondary structure characterised by two beta sheets from a.a. 3 to a.a. 5, i.e. ${ }_{3} \mathrm{NVH}_{5}$, and from a.a. 11 to a.a. 12, i.e. ${ }_{11} \mathrm{AT}_{12}$ (Fig. 1A), respectively. Tertiary structures of JCPyV capsidic viral protein VP 1 was retrieved from the PDB structures available. Mapping of the linear peptides on the inferred protein structure showed that VP1 K and VP1 N do not fold in any type of structure (Fig. 1B, C). A three dimensional graphic rendering of the peptides mapped on the VP 1 native structure showed that a.a. residues are exposed to the environment on the surface of the VP1 protein (Fig. 1D).

\section{Detection of JCPyV antibodies by indirect ELISA}

In order to verify whether human sera contain IgG antibodies reacting to JCPyV peptides and to determine the spread of JCPyV infection in humans, indirect ELISA was set up employing synthetic peptides. Selected peptides JCPyV VP1 mimotopes K and N, and an unrelated human peptide, known as hNPS, used as a negative control, were employed in ELISA (Fig. 2A) (Guerrini et al., 2010).

The indirect ELISA was employed to test serum samples taken from HS, ranging from 2-100 years old, which had been diluted at 1/20, for reactivity to JCPyV VP1 epitopes. Serum samples, which reacted to JCPyV VP1 K mimotope reached an overall prevalence of 42\% (150/355). The same assay was employed to detect the serum IgG class antibodies against JCPyV mimotope VP1 N. It turned out that serum samples reacted with the VP1 N peptide with a similar prevalence, $43 \%$ (151/355), as had been detected previously for the VP1 K peptide. Conversely, seronegative samples for the JCPyV VP1 K peptide failed to react with JCPyV VP1 N epitopes. A few serum 
samples were exceptions. Sera $(n=23)$ were found to be negative for VP1 K, while testing positive for VP1 N peptide, and vice-versa. The difference was not statistically significant $(P>0.05)$ (Table $1)$.

Combining JCPyV-positive sera, both for VP1 K and VP1 N peptides, the overall prevalence was 39\% (Table 1). The two indirect ELISA tests, with two distinct VP peptides gave overlapping results, thus confirming the presence of anti-JCPyV VP1 antibodies in human sera from healthy adult subjects (Table 1).

A prevalence selection corresponding to $32 \%, 46 \%, 54 \%$, and $28 \%$, within the cohort ranging from 2-100 years old, was observed in cohorts of subjects aged 2-10, 11-30, 31-65 and 66-100 years old, respectively. Interestingly, the prevalence of serum antibodies against JCPyV VP1 declined in the cohort of individuals aged 66-100 years old, showing a prevalence of 28\% (Table 1).

JCPyV-positive sera tested by indirect ELISA diluted at 1/20 had a general cut-off in the range of 0.17 OD by spectrophotometric reading. This cut-off represents the value that discriminates JCPyVnegative from JCPyV-positive samples. The positive control, represented by the JCPyV hyperimmune rabbit serum, had an OD of up to 0.3, while BKPyV and SV40 hyperimmune sera, which were employed as negative controls, had an OD $<0.01-0.015$.

In this investigation, JCPyV seroprevalence increased up to the cohort of subjects aged 31-65 years old, while decreasing in elderly individuals aged 66-100 years old (Table 1). These differences are statistically significant comparing the distinct cohorts of individuals of different age (2-10 vs. 31-65 ys, $P=0.007 ; 11-30$ vs. $66-100$ ys, $P=0.016$; and $31-65$ vs. $66-100$ ys, $P=0.0006$ ) (Table 1$)$.

Serologic profiles of serum antibody reactivity to JCPyV mimotopes (Fig. 3) indicate that the OD mean increases with the age in the cohort of HS ranging from 31-65 years old, whereas the OD value decreases in older HS, aged 66-100 years old. High levels of antibodies against VP1 K, VP1 $\mathrm{N}$ and VP1 $\mathrm{K}+\mathrm{N}$ were present in HS aged 31-65 years old compared to HS aged 2-10 years old, whereas high levels of antibodies against VP1 N and VP1 $\mathrm{K}+\mathrm{N}$ were observed in HS aged 31-65 
years old compared to HS 66-100 years old. The antibody prevalence and titer increase with the age in HS aged up to 65 years old, then they decline in older HS, aged 66-100 years old.

The intra-run variability, analyzed by t-test, was not statistically significant for both peptides K and $\mathrm{N}$, with $\mathrm{P}$ values 0.22 and 0.8 , respectively. (Fig. 4A). The inter-run variability, analyzed with Anova and Holm Sidak corrected for multiple comparison, was not statistically significant for peptides $\mathrm{K}$ and $\mathrm{N}$, with $\mathrm{P}$ values 0.45 and 0.97 , respectively (Fig. 4B).

\section{Prevalence of serum antibody against JCPyV determined by the Haemagglutination inhibition (HAI) assay}

Human sera, analyzed using the Haemagglutination Inhibition (HAI) assay, were serially diluted from $1: 16 ; 1: 32 ; 1: 64 ;$ to $1: 128$. HAI assay evaluates both the presence and titer of antibodies against JCPyV. This assay was carried out as a control to check the data obtained with the new indirect ELISA. To this end, 89 randomly selected sera out of 355 samples assayed by indirect ELISA were tested by HAI assay. The seroprevalence of JCPyV-positive samples, diluted 1:128, was 51\% (45/89) (Table 2). Interestingly, the prevalence of JCPyV-positive samples obtained by HAI did not differ from that determined by the innovative indirect ELISA with mimotopes $(P>0.05)$. Concordance of the JCPyV prevalence obtained with the two techniques was $100 \%$. Indeed, JCPyV-positive $(n=45)$ and JCPyV-negative $(n=44)$ sera were obtained by HAI and indirect ELISA. However, the false-positive and false-negative rates were $4 \%(2 / 45)$ and $7 \%(3 / 44)$, respectively. Moreover, the indirect ELISA and HAI assays showed good rates of sensibility and specificity, which were $96 \%$ (43/45) and 93\% (41/44), respectively. 


\section{Discussion}

JCPyV VP1 K and VP1 N mimotopes, as linear peptides (Fig. 1A), were computationally analysed for their secondary structure, whereas JCPyV viral protein 1 (VP 1) was investigated for its tertiary structure. These analyses revealed that VP1 K and VP1 N have secondary structures similar to that found in their VP1 native protein. The two mimotopes contain beta-sheet domains formed by few a.a. residues (Figs 1B, C). The three dimensional mesh surface visualisation (Fig. 1D) of the VP1 protein tertiary structure, in which the two linear peptides are mapped, showed that the a.a. chains, which were analysed, are exposed to the environment. This position may represents a short of docking sites for immunological reactions. These results may suggest that the linear peptides VP1 K and VP1 N could resemble natural JCPyV VP1 capsidic epitopes constituting a docking site for serum antibodies.

The three JCPyV, BKPyV and SV40 Polyomaviruses show significant sequence homology. Indeed, upon comparison of the entire viral genome, DNA sequence identity is $72 \%$ between BKV and JCV, 69\% between BKV and SV40 and 68\% between JCPyV and SV40 (Barbanti-Brodano et al., 2006). This high homology and the cross-reactivity of previous immunologic tests with VLPs/rVP1 prompted us to develop a JCPyV specific indirect ELISA, with synthetic peptides as antigens, instead of VLPs or soluble recombinant VP1 (Fig. 2B, C).

Human sera were analysed for IgG antibodies, which react to two JCPyV VP1 mimotopes K and N. To this purpose, an indirect ELISA was set up employing synthetic peptides, which correspond to specific JCPyV VP 1 antigens. As a reaction control, the unrelated human neuropeptide hNPS was used as a negative control.

The objective of the present study was to investigate whether serum samples from HS ranging18100 years old carry specific JCPyV-antibodies. Sera were analyzed using two different methods, an indirect ELISA with two mimotopes, which correspond to VP1 antigens and by Haemagglutination Inhibition (HAI) assay (Corallini et al., 2012). The HAI method was employed to verify the JCPyP 
specificity and to confirm the data obtained using the innovative ELISA with synthetic peptides as mimotopes of the JCPyV viral capsid proteins 1 (VP1).

On this basis, serum samples from HS were analyzed for their reactivity to JCPyV epitopes from viral capsid VP1 proteins using indirect ELISA testing. Data indicate that the overall prevalence of JCPyV-VP1 antibodies in the HS cohorts involved in the study, aged from 2-100 years old, is 39\%. Negative results were obtained with sera assayed with the human neuropeptide hNPS employed as control antigen. No reactivity was detected using SV40- and BKPyV-positive sera challenged against JCPyV mimotopes $\mathrm{K}$ and $\mathrm{N}$, whereas JCPyV-positive serum specifically reacted with both mimotopes. In this investigation, JCPyV-positive and JCPyV-negative sera were detected without cross-reactivity, by the new indirect ELISA with two synthetic peptides, JCPyV mimotopes K and N.

Subsequently, human sera from HS were analysed by Haemagglutination Inhibition (HAI) assay as a control. This assay enables immune serum antibodies to be detected against JCPyV, which abolish its agglutination property. The seroprevalence of JCPyV-positive samples, diluted 1:128, was 51\% (45/89) in HS. HAI data were compared to those obtained by indirect ELISA. The seroprevalence of JCPyV-positive samples from HS determined by HAI overlapped data obtained by indirect ELISA with synthetic peptides corresponding to the VP1 epitopes $(P>0.05)$. Interestingly, the concordance of JCPyV-positive samples obtained using the two techniques was $100 \%$. (Tables 1 and 2). This result confirms that the new indirect ELISA is a specific, sensitive and reliable method. Taken together, the data from the ELISA test indicate that in normal individuals natural JCPyV infection occurs at a high prevalence (39\%). The prevalence of anti-JCPyV serum antibodies increases with age, reaching 54\% in the HS cohort ranging from 31-65 years old, with an increase of JCPyV antibody level determined by OD readings. Subsequently, seroprevalence decreases significantly in elderly subjects, until seroprevalence is $28 \%$ in the HS cohort ranging from 66-100 years old. The serological profile shows the same trend, i.e., the OD mean and therefore the antibody titer tends to increase with age, with an increase in the HS cohort ranging from 31-65 
years old. On the other hand, the OD mean decreases in the HS cohort of 66-100 years old. Antibody prevalence and titer increase with age, up to 65 years old, then both parameters decline in the elderly.

Our data differ from other immunological studies where JCPyV antibody prevalence was obtained using ELISA with VLP/VP1. Previous data could have been affected by technical issues. Indeed, earlier results were mainly obtained with recombinant VLPs or VP1 as antigens, which contain many epitopes in common with JCPyV, BKPyV and SV40.

The innovative indirect ELISA with JCPyV VP1 mimotopes reported herein is a new useful method to detect specific IgG antibodies against this virus in human sera from healthy subjects, without cross-reactivity with the closely related BKPyV and SV40 polyomaviruses.

We may envision that this new indirect ELISA with synthetic peptides, which is highly specific in detecting JCPyV antibodies, will be useful to analyze sera from tumor affected patients. Investigators may benefit from new immunological studies to check an association between JCPyV, brain tumors and colorectal carcinomas. Furthermore, JCPyV is the causal agent of polyomavirusassociated nephropathy. Indeed, kidney transplant patients are at risk of premature allograft failure (Castro et al., 2017; Funahashi et al., 2016). At risk patients can be identified before significant functional impairment of the renal allograft occurs (Castro et al., 2017; Chan et al., 2015; Funahashi et al., 2016; Querido et al., 2015; Saundh et al., 2016). Our innovative ELISA with JCPyV VP1 mimotopes will be useful to study multiple sclerosis (MS) affected patients treated with monoclonal antibodies (mab), such as the natalizumab (Reuwer et al., 2017). Indeed, it well known that this mab may depress the immune system of MS patients (Tan and Koralnik, 2010; White and Khalili, 2011). The new ELISA could be employed for risk stratification of SM patients who are at risk of developing progressive multifocal leukoencephalopathy (PML) by JCPyV reactivation/infection (Gorelik et al., 2010). 


\section{CONFLICT OF INTEREST STATEMENT}

Data of this work were enclosed, in part, in the Italian patent application number I0167479/BREEC/rp, filed on August 9, 2016.

\section{ACKNOWLEDGMENTS}

Dr. Elisa Mazzoni was a fellowship recipient of the Fondazione Umberto Veronesi, Milan. The researchers involved in this study would like to thank Dr. Eugene O. Major, the Laboratory of Molecular Medicine and Neuroscience, the National Institute of Neurological Disorders and Stroke, Bethesda, MD, for the hyperimmune serum against JCPyV. 


\section{REFERENCES}

Barbanti-Brodano G, Sabbioni S, Martini F, Negrini M, Corallini A, Tognon M. 2006. BK virus, JC virus and Simian Virus 40 infection in humans, and association with human tumors. Adv Exp Med Biol 577:319-341.

Berman HM, Bhat TN, Bourne PE, Feng Z, Gilliland G, Weissig H, Westbrook J. 2000. The Protein Data Bank and the challenge of structural genomics. Nat Struct Biol 7 Suppl:957-959.

Bollag B, Prins C, Snyder EL, Frisque RJ. 2000. Purified JC virus T and T' proteins differentially interact with the retinoblastoma family of tumor suppressor proteins. Virology 274(1):165-178.

Boukoum H, Nahdi I, Sahtout W, Skiri H, Segondy M, Aouni M. 2016. BK and JC virus infections in healthy patients compared to kidney transplant recipients in Tunisia. Microbial pathogenesis 97:204-208.

Bouvard V BR, Grosse Y, Lauby-Secretan B, El Ghissassi F, Benbrahim-Tallaa L, Guha N, Straif K. 2012. WHO International Agency for Research on Cancer Monograph Working Group. Carcinogenicity of malaria and of some polyomaviruses. Lancet Oncol 13:339-340.

Bryson K, McGuffin LJ, Marsden RL, Ward JJ, Sodhi JS, Jones DT. 2005. Protein structure prediction servers at University College London. Nucleic Acids Res 33(Web Server issue):W36-38.

Castro T, Fink MC, Figueiredo M, Braz-Silva PH, Pannuti CM, Ortega KL, Gallottini M. 2017. Polyomavirus BK and $\mathrm{JC}$ in individuals with chronic kidney failure, kidney transplantation, and healthy controls. J Clin Virol 89:5-9.

Chan JF, Ma MK, Chan GS, Chan GC, Choi GK, Chan KH, Cheng VC, Chan KW, Choy BY, Yuen KY. 2015. Rapid reduction of viruria and stabilization of allograft function by fusidic acid in a renal transplant recipient with JC virus-associated nephropathy. Infection 43(5):577-581.

Clausi V, Giannecchini S, Magnani E, Repice A, Mechi C, Martelli F, Azzi A, Massacesi L. 2015. Markers of JC virus infection in patients with multiple sclerosis under natalizumab therapy. Neurology(R) neuroimmunology \& neuroinflammation 2(1):e58.

Clavel G, Moulignier A, Semerano L. 2017. Progressive multifocal leukoencephalopathy and rheumatoid arthritis treatments. Joint, bone, spine : revue du rhumatisme.

Clerico M, Artusi CA, Liberto AD, Rolla S, Bardina V, Barbero P, Mercanti SF, Durelli L. 2017. Natalizumab in Multiple Sclerosis: Long-Term Management. International journal of molecular sciences 18(5).

Corallini A, Mazzoni E, Taronna A, Manfrini M, Carandina G, Guerra G, Guaschino R, Vaniglia F, Magnani C, Casali F, Dolcetti R, Palmonari C, Rezza G, Martini F, Barbanti-Brodano G, Tognon MG. 2012. Specific antibodies reacting with simian virus 40 capsid protein mimotopes in serum samples from healthy blood donors. Hum Immunol 73(5):502-510.

Coursaget P, Samimi M, Nicol JT, Gardair C, Touze A. 2013. Human Merkel cell polyomavirus: virological background and clinical implications. APMIS : acta pathologica, microbiologica, et immunologica Scandinavica 121(8):755-769.

Del Valle L, Enam S, Lara C, Ortiz-Hidalgo C, Katsetos CD, Khalili K. 2002. Detection of JC polyomavirus DNA sequences and cellular localization of T-antigen and agnoprotein in oligodendrogliomas. Clinical cancer research : an official journal of the American Association for Cancer Research 8(11):33323340.

Delbue S, Comar M, Ferrante P. 2017. Review on the role of the human Polyomavirus JC in the development of tumors. Infectious agents and cancer 12:10.

Delbue S, Ferraresso M, Ghio L, Carloni C, Carluccio S, Belingheri M, Edefonti A, Ferrante P. 2013. A review on JC virus infection in kidney transplant recipients. Clinical \& developmental immunology 2013:926391.

Egli A, Infanti L, Dumoulin A, Buser A, Samaridis J, Stebler C, Gosert R, Hirsch HH. 2009. Prevalence of polyomavirus BK and JC infection and replication in 400 healthy blood donors. J Infect Dis 199(6):837-846.

Ferenczy MW, Marshall LJ, Nelson CD, Atwood WJ, Nath A, Khalili K, Major EO. 2012. Molecular biology, epidemiology, and pathogenesis of progressive multifocal leukoencephalopathy, the JC virusinduced demyelinating disease of the human brain. Clin Microbiol Rev 25(3):471-506. 
Frisque RJ, Bollag B, Tyagarajan SK, Kilpatrick LH. 2003. T' proteins influence JC virus biology. J Neurovirol 9 Suppl 1:15-20.

Funahashi Y, Kato M, Fujita T, Ishida S, Mori A, Gotoh M. 2016. Association Between the Polyomaviruses Titers and Decoy Cell Positivity Rates After Renal Transplantation. Transplantation proceedings 48(3):921-923.

Gasteiger E, Gattiker A, Hoogland C, Ivanyi I, Appel RD, Bairoch A. 2003. ExPASy: The proteomics server for in-depth protein knowledge and analysis. Nucleic Acids Res 31(13):3784-3788.

Gorelik L, Lerner M, Bixler S, Crossman M, Schlain B, Simon K, Pace A, Cheung A, Chen LL, Berman M, Zein F, Wilson E, Yednock T, Sandrock A, Goelz SE, Subramanyam M. 2010. Anti-JC virus antibodies: implications for PML risk stratification. Ann Neurol 68(3):295-303.

Guerrini R, Salvadori S, Rizzi A, Regoli D, Calo G. 2010. Neurobiology, pharmacology, and medicinal chemistry of neuropeptide $S$ and its receptor. Med Res Rev 30(5):751-777.

Hegen H, Auer M, Bsteh G, Di Pauli F, Plavina T, Walde J, Deisenhammer F, Berger T. 2017. Stability and predictive value of anti-JCV antibody index in multiple sclerosis: A 6-year longitudinal study. PLoS One 12(3):e0174005.

Jones DT. 1999. Protein secondary structure prediction based on position-specific scoring matrices. J Mol Biol 292(2):195-202.

Kean JM, Rao S, Wang M, Garcea RL. 2009. Seroepidemiology of human polyomaviruses. PLoS Pathog 5(3):e1000363.

Knowles WA. 2006. Discovery and epidemiology of the human polyomaviruses BK virus (BKV) and JC virus (JCV). Adv Exp Med Biol 577:19-45.

Maginnis MS, Stroh L, Gee GV, O'Hara BA, Derdowski A, Stehle T, Atwood WJ. 2013. Progressive multifocal leukoencephalopathy-associated mutations in the JC polyomavirus capsid disrupt lactoseries tetrasaccharide $\mathrm{c}$ binding. mBio 4(3):e00247-00213.

Martini F, Mazzoni E, Corallini A, Taronna A, Querzoli P, Magri E, Marci R, Dolcetti R, Rezza G, BarbantiBrodano G, Tognon M. 2013. Breast cancer and simian virus 40 infection. Epidemiology 24(3):464465.

Mazzoni E, Corallini A, Cristaudo A, Taronna A, Tassi G, Manfrini M, Comar M, Bovenzi M, Guaschino R, Vaniglia F, Magnani C, Casali F, Rezza G, Barbanti Brodano G, Martini F, Tognon M. 2012. High prevalence of serum antibodies reacting wuth simian virus 40 capsid protein minotopes in patients affected by malignant pleural mesothelioma. Proc Natl Acad Sci U S A 109(44):18066-18071.

Neu U, Maginnis MS, Palma AS, Stroh LJ, Nelson CD, Feizi T, Atwood WJ, Stehle T. 2010. Structure-function analysis of the human JC polyomavirus establishes the LSTC pentasaccharide as a functional receptor motif. Cell Host Microbe 8(4):309-319.

Newcomb PA, Bush AC, Stoner GL, Lampe JW, Potter JD, Bigler J. 2004. No evidence of an association of JC virus and colon neoplasia. Cancer Epidemiol Biomarkers Prev 13(4):662-666.

Padgett BL, Walker DL, ZuRhein GM, Eckroade RJ, Dessel BH. 1971. Cultivation of papova-like virus from human brain with progressive multifocal leucoencephalopathy. Lancet 1(7712):1257-1260.

Pietrobon S, Bononi I, Lotito F, Perri P, Violanti S, Mazzoni E, Martini F, Tognon M. 2017a. Specific detection of serum antibodies against BKPyV, a small DNA tumour virus, in patients affected by choroidal nevi. Frontiers in microbiology In press.

Pietrobon S, Bononi I, Mazzoni E, Lotito F, Manfrini M, Puozzo A, Destro F, Guerra G, Nocini PF, Martini F, Tognon MG. 2017b. Specific IgG Antibodies React to Mimotopes of BK Polyomavirus, a Small DNA Tumor Virus, in Healthy Adult Sera. Frontiers in immunology 8:236.

Pinto M, Dobson S. 2014. BK and JC virus: a review. The Journal of infection 68 Suppl 1:S2-8.

Plavina T, Subramanyam M, Bloomgren G, Richman S, Pace A, Lee S, Schlain B, Campagnolo D, Belachew S, Ticho B. 2014. Anti-JC virus antibody levels in serum or plasma further define risk of natalizumabassociated progressive multifocal leukoencephalopathy. Ann Neurol 76(6):802-812.

Portolani M, Marzocchi A, Barbanti-Brodano G, La Placa M. 1974. Prevalence in Italy of antibodies to a new human papovavirus (BK virus). Journal of medical microbiology 7(4):543-546.

Prins C, Frisque RJ. 2001. JC virus $T^{\prime}$ proteins encoded by alternatively spliced early mRNAs enhance $T$ antigen-mediated viral DNA replication in human cells. J Neurovirol 7(3):250-264. 
Querido S, Jorge C, Sousa H, Birne R, Matias P, Weigert A, Adragao T, Bruges M, Ramos S, Santos M, Paixao P, Curran MD, Machado D. 2015. JC polyomavirus nephropathy confirmed by using an in-house polymerase chain reaction method. Transplant infectious disease : an official journal of the Transplantation Society 17(5):732-736.

Reuwer AQ, Heron M, van der Dussen D, Schneider-Hohendorf T, Murk JL. 2017. The clinical utility of JC virus antibody index measurements in the context of progressive multifocal leukoencephalopathy. Acta Neurol Scand 136 Suppl 201:37-44.

Ricciardiello L, Baglioni M, Giovannini C, Pariali M, Cenacchi G, Ripalti A, Landini MP, Sawa H, Nagashima K, Frisque RJ, Goel A, Boland CR, Tognon M, Roda E, Bazzoli F. 2003. Induction of chromosomal instability in colonic cells by the human polyomavirus JC virus. Cancer Res 63(21):7256-7262.

Ripple MJ, Parker Struckhoff A, Trillo-Tinoco J, Li L, Margolin DA, McGoey R, Del Valle L. 2014. Activation of C-Myc and Cyclin D1 by JCV T-Antigen and beta-catenin in colon cancer. PloS one 9(9):e106257.

Rodio DM, Anzivino E, Mischitelli M, Bellizzi A, Scrivo R, Scribano D, Conte G, Prezioso C, Trancassini M, Valesini G, Palamara AT, Pietropaolo V. 2016. Increased Prevalence of Human Polyomavirus JC Viruria in Chronic Inflammatory Rheumatic Diseases Patients in Treatment with Anti-TNF alpha: A 18 Month Follow-Up Study. Frontiers in microbiology 7:672.

Saundh BK, Baker R, Harris M, Hale A. 2016. A prospective study of renal transplant recipients reveals an absence of primary JC polyomavirus infections. J Clin Virol 77:101-105.

Stolt A, Sasnauskas K, Koskela P, Lehtinen M, Dillner J. 2003. Seroepidemiology of the human polyomaviruses. J Gen Virol 84(Pt 6):1499-1504.

Tan CS, Koralnik IJ. 2010. Progressive multifocal leukoencephalopathy and other disorders caused by JC virus: clinical features and pathogenesis. Lancet Neurol 9(4):425-437.

Taronna A, Mazzoni E, Corallini A, Bononi I, Pietrobon S, Guerra G, Palmonari C, Borgna-Pignatti C, Comar M, Bovenzi M, Casali F, Marci R, Rezza G, Barbanti-Brodano G, Tognon M, Martini F. 2013. Serological evidence of an early seroconversion to Simian virus 40 in healthy children and adolescents. PloS one 8(4):e61182.

Toumi W, Ripalti A, Ricciardiello L, Cherif A, Gargouri D, Bouhafa A, Kharrat J, Jarboui S, Benrhouma H, Zili $M$, Khelifa R. 2017. Detection of a new JCV strain of genotype A in a subpopulation of colorectal adenocarcinomas in Tunisia. The new microbiologica 40(2).

Touze A, Gaitan J, Arnold F, Cazal R, Fleury MJ, Combelas N, Sizaret PY, Guyetant S, Maruani A, Baay M, Tognon M, Coursaget P. 2010. Generation of Merkel cell polyomavirus (MCV)-like particles and their application to detection of MCV antibodies. Journal of clinical microbiology 48(5):1767-1770.

Trowbridge PW, Frisque RJ. 1995. Identification of three new JC virus proteins generated by alternative splicing of the early viral mRNA. J Neurovirol 1(2):195-206.

Viscidi RP, Rollison DE, Sondak VK, Silver B, Messina JL, Giuliano AR, Fulp W, Ajidahun A, Rivanera D. 2011. Age-specific seroprevalence of Merkel cell polyomavirus, BK virus, and JC virus. Clin Vaccine Immunol 18(10):1737-1743.

Viscidi RP, Rollison DE, Viscidi E, Clayman B, Rubalcaba E, Daniel R, Major EO, Shah KV. 2003. Serological cross-reactivities between antibodies to simian virus 40 , BK virus, and JC virus assessed by viruslike-particle-based enzyme immunoassays. Clin Diagn Lab Immunol 10(2):278-285.

Wang HT, Chang JW, Guo Z, Li BG. 2007. In silico-initiated cloning and molecular characterization of cortexin 3, a novel human gene specifically expressed in the kidney and brain, and well conserved in vertebrates. Int J Mol Med 20(4):501-510.

White MK, Khalili K. 2011. Pathogenesis of progressive multifocal leukoencephalopathy--revisited. J Infect Dis 203(5):578-586.

White MK, Sariyer IK, Gordon J, Delbue S, Pietropaolo V, Berger JR, Khalili K. 2016. Diagnostic assays for polyomavirus JC and progressive multifocal leukoencephalopathy. Rev Med Virol 26(2):102-114. 
Tables

TABLE 1. Prevalence of immunoglobulin G antibodies reacting in indirect ELISA to JC virus (JCPyV) viral capsid protein 1 (VP 1) mimotopes.

\begin{tabular}{llcccc}
\hline $\begin{array}{l}\text { Age } \\
\text { (years) }\end{array}$ & $\begin{array}{c}\text { Number of } \\
\text { samples }\end{array}$ & $\begin{array}{c}\text { Male } \\
\%\end{array}$ & \multicolumn{2}{c}{ Number of positive samples (\%) } \\
\hline & & & & & \\
& & & & & \\
$2-10$ & 82 & 49 & $26(32)$ & $27(33)$ & $26(32)^{* *}$ \\
$11-30$ & 90 & 40 & $44(49)$ & $42(47)$ & $41(46)$ \\
$31-65$ & 82 & 37 & $49(60)$ & $53(65)$ & $44(54)$ \\
$66-100$ & 101 & 52 & $31(31)$ & $29(29)$ & $28(28)^{* \circ}$ \\
$2-100$ & 355 & 45 & $150(42)$ & $151(43)$ & $139(39)$ \\
& & & & & \\
\hline
\end{tabular}

Human sera were from healthy subjects. Statistical analysis was performed using the chi-square test with Yates' correction. The prevalence of JCPyV antibodies detected in the cohort of individuals 11-30 years old is statistically lower from that revealed in the cohorts of subjects 66-100 years old $\left({ }^{*} P=0.016\right)$ and $31-65$ years old $\left({ }^{\circ} P=0.0006\right)$, respectively. The prevalence of JCPyV antibodies in the cohort of individuals 2-10 years old is statistically lower compared to that of the cohort 31-65 years old $(* * P=0.007)$. 
TABLE 2. Prevalence of serum IgG antibodies against JCPyV analyzed by haemagglutination inhibition (HAI) assay.

\begin{tabular}{|c|c|c|c|c|c|c|}
\hline \multirow{2}{*}{$\begin{array}{l}\text { Number of } \\
\text { serum } \\
\text { sample }\end{array}$} & \multirow[t]{2}{*}{$\begin{array}{c}\text { Median } \\
\text { age } \pm \text { SD }\end{array}$} & \multirow[t]{2}{*}{$\begin{array}{l}\text { Male } \\
(\%)\end{array}$} & \multicolumn{4}{|c|}{$\begin{array}{c}\text { Number of positive sample/sample analyzed (\%) } \\
\text { at the dilution indicated }\end{array}$} \\
\hline & & & $1: 16$ & $1: 32$ & $1: 64$ & $1: 128$ \\
\hline 89 & $65 \pm 13$ & 60 & $79 / 89$ (89) & $78 / 89(88)$ & $69 / 89$ (77) & $45 / 89(51)$ \\
\hline
\end{tabular}

Samples analyzed using hemagglutination inhibition assay. Human sera were from healthy subjects. The dilution 1:128 has been chosen because lower dilutions, such as 1:32 or 1:64, contain antibodies at higher concentration, which may give rise to false positive reaction (Pietrobon et al., 2017a; Pietrobon et al., 2017b) 


\section{Figures' Legends}

Fig. 1. Computational analysis carried out on JCPyV synthetic peptides by PSIPRED. Panel A: Peptides VP1 K and VP1 N show many random coiled domains with beta-sheets. Panels B and C: Peptides VP1 K (B) and VP1 N (C) are shown in blue in a detailed view, within JCPyV VP1 3D model. Panel D: Mesh surface model of JCPyV VP1 protein; VP1 K and VP1N are marked in blue and red, respectively. The structure of both peptides $\mathrm{K}$ and $\mathrm{N}$ and their mapping on the native protein VP1 surface are shown.

Fig. 2. Amino acid (a.a.) sequences of the two different peptides, $\mathrm{K}$ and $\mathrm{N}$, of the viral protein 1 (VP1) of JC Polyomavirus (JCPyV) and polyomaviruses phylogenetic tree.

Panels A and B. The peptides K and N, represented in panel A, were selected on the basis of their low homology with the corresponding peptides from other human/simian polyomaviruses shown in panel B.

The novel enzyme-linked immunosorbent assay (ELISA) indicated that only VP1 K and VP1 N peptides, used as mimotopes, reacted to serum IgG antibodies without cross-reaction with BKPyV and SV40 hyperimmune sera employed as controls. Indeed, SV40 and BKPyV hyperimmune sera, the negative controls, analyzed by ELISAs gave OD values $<0.015$.

Panel C. Representation of the polyomaviruses phylogenetic tree. The similarity of VP1 a.a. sequences among different polyomaviruses is shown. JCPyV VP1 is more closely related to those of SV40, SV12 and BKPyV compared to other polyomavirus VP1, such as KIPyV, WUPyV, HPyV11/STLPyV, HPyV10, HPyV7, HPyV6, HPyV9, LPV/AGMPyV, TSPyV, MCPyV, HPyV12, and NJPyV (not shown). 
Fig. 3. Serologic profile of human serum antibody reactivity to JCPyV mimotopes VP1 K VP1 N and VP1 K+N. Immunologic data are from healthy subjects (HS). Results are presented as values of OD readings at $\lambda 405 \mathrm{~nm}$ for serum samples diluted 1:20 and assayed in indirect ELISA. In this scatter dot plotting, each plot represents the dispersion of individual sample OD values to a mean level, indicated by the long horizontal line inside the scatter with standard error of the mean (SEM) marked by short horizontal lines for each age group. The OD readings of serum samples were stratified by age: 2-10 years (yrs), 11-30 yrs, 31-65 yrs, and 66-100 yrs. Data were analyzed with one way Anova analysis and Tukey’s multiple comparison test (OD mean, 95\% CI). (A) High levels of antibodies against VP1 K in HS aged 31-65 yrs $(0.23 \mathrm{OD}, 95 \% \mathrm{CI}=0.19-0.26)$ vs. HS aged 2-10 yrs $(0.17 \mathrm{OD}, 95 \% \mathrm{CI}=0.14-0.19, \mathrm{P}=0.01)$. (B) High levels of antibodies against VP1 $\mathrm{N}$ in HS aged $31-65$ yrs $(0.25 \mathrm{OD}, 95 \% \mathrm{CI}=0.22-0.28)$ vs. HS aged $2-10 \mathrm{yrs}(0.18 \mathrm{OD}, 95 \% \mathrm{CI}=$ $0.15-0.20, \mathrm{P}=0.005)$ and vs. HS aged $66-100 \mathrm{yrs}(0.19 \mathrm{OD}, 95 \% \mathrm{CI}=0.16-0.21, \mathrm{P}=0.01) .(\mathbf{C})$ High levels of antibodies against VP1 $\mathrm{K}+\mathrm{N}$ in $\mathrm{HS}$ aged $31-65$ yrs $(0.24 \mathrm{OD}, 95 \% \mathrm{CI}=0.22-0.26)$ vs. HS aged $2-10 y r s(0.17 \mathrm{OD}, 95 \% \mathrm{CI}=0.15-0.19, \mathrm{P}<0.0001)$ and vs. HS aged $66-100 \mathrm{yrs}(0.18$ $\mathrm{OD}, 95 \% \mathrm{CI}=0.17-0.20, \mathrm{P}=0.0006)$

Fig. 4. Intra-run (A) and inter-run (B) variability of OD values of human serum antibody reactivity to VP1 K and VP1 N peptides. Data are presented as scatter dot plot of OD readings at $\lambda 405 \mathrm{~nm}$, mean and standard error of the mean (SEM) marked by short horizontal lines for each peptide. (A) OD value variability, intra-run. $\mathrm{VP} 1 \mathrm{~K}:$ mean $=0.19, \mathrm{SEM}=0.007 ; \mathrm{VP} 1 \mathrm{~N}:$ mean $=0.16$; $\mathrm{SEM}=$ 0.005. (B) OD value variability, inter-run. VP1 $\mathrm{K}$ : mean $=0.18, \mathrm{SEM}=0.004$; VP1 $\mathrm{N}$ : mean $=$ $0.16, \mathrm{SEM}=0.003$. 